D. MCINTOSH.

The results obtained from these experiments agree, in general, with facts already known. The work has value chiefly, as it seems to me, in the collection of definite data for future investigation rather than in any new facts brought to light by the figures given.

WELIESLEY COLLEGK, June, I903.

\title{
A LECTURE EXPERIMENT WITH AN UNDISSOCIATED
}

\section{SALT.}

By D. MeIntosh.

Received June $18,1903$.

WHEN a sulphocyanate is added to a ferric salt, the deep red color produced is thought, for a number of reasons, to be due to the undissociated ferric sulphocyanate. These may be briefly stated: First, neither the ferric nor the sulphocyanate ion is colored; second, the crystals of ferric sulphocyanate, which can contain no ions, are similarly colored; third, in ether, in which salts are but slightly dissociated, the color is unchanged; fourth. an excess of a sulphocyanate increases the color, while the ardition of sulphate ions weakens it.

If, then, ferric sulphocyanate were placed in a tube between two layers of a colorless liquid, the passage of a current should not increase the rate of diffusion; if, on the other hand, the color were due to a complex cation or anion, the color should move either to the cathode or anode.

If a solution of ferric sulphocyanate be placed in a $U$-tube, and carefully covered over with a less dense electrolyte (dilute hydrochloric acid), a current of $1 / 100$ ampere may be passed through it for several hours without the relative positions of the colorboundaries changing. The experiment can be made quite striking, by arranging in series two other tubes containing ${ }^{1}$ potassium copper tartrate covered with dilute potassium hydroxide, and copper sulphate with ammonium hydroxide covered with ammonium hydroxide. In the first case, the color-boundaries remain stationary, while in the second and third they move towards the anode and ca:hode respectively.

1 Massoni : Ztschr. phys. Chem., 29, 501 (1899). 
In the figure is shown a $U$-tube of a convenient pattern, after Nernst. The lighter liquid is introduced first through the side tube. That the color is due to the undissociated salt is confirmed by conductivity and molecular-weight determinations. The conductivities of mixtures of ferric chloride and ammonium sulphocyanate were 20 to 30 per cent. less than their mean conductivities,

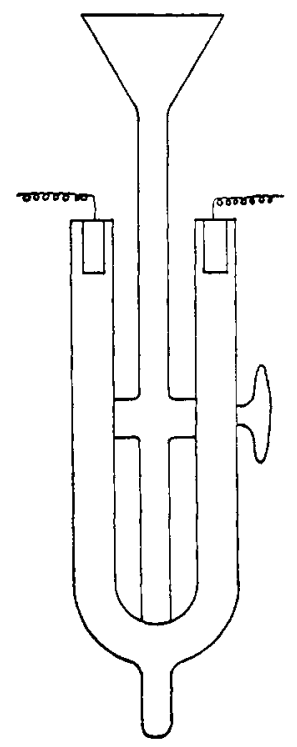

while the rise in boiling-point of a mixture of the two salts is always much less than the sum of the rise in boiling-points due to the two substances taken separately.

MCGILI UNIVERSITY,

Montreal, April 25, 1903.

\section{NOTES.}

Note on Carbon Combustion in a Platinum Crucible.-In a recent paper ${ }^{1}$ John V. R. Stehman, referring to the writer's special crucible $^{2}$ for carbon combustion, makes the statement that "the prevalent idea regarding his form of apparatus seems to be a fear of the rubber gasket causing error by burning directly or by be-

1 This Journal, 25, 237 .

2 Ibid., 23, 227, and 21, 557. 